\title{
PRESENTE DE LAS POLITICAS DE IGUALDAD EN ÁMBITO LOCAL DE LA COMUNIDAD DE MADRID
}

\author{
Cándida Gago García \\ Departamento de Análisis Geográfico Regional y Geografía Física. Universidad Complutense de Madrid \\ cgago@ghis.ucm.es \\ Juana $\mathbf{M}^{\mathrm{a}}$ Rodríguez Moya \\ Departamento Geografía Humana. Universidad Complutense de Madrid. \\ jumrodri@ghis.ucm.es
}

\section{RESUMEN}

Este artículo aborda las políticas locales de igualdad actuales en los municipios de la Comunidad de Madrid. El estudio se centra en el análisis de distintos aspectos, por ejemplo, la implantación y existencia de una concejalía individualizada y visible de la Mujer, la comparación de diferentes Planes de Igualdad de Oportunidades entre mujeres y hombres elaborados por las administraciones locales, y de distintos programas como el de atención integral a mujeres víctimas de violencia de género o los programas de conciliación de la vida laboral y personal; también se incluyen en el análisis otro tipo de iniciativas locales destinadas a mujeres, como talleres o servicios de formación para el empleo. El enfoque desarrollado, de carácter analítico, valora diferentes variables, como el estado de implantación geográfica y grado de desarrollo de las políticas y la capacidad, a priori, que éstas últimas tienen de contribuir al empoderamiento y facilitar la consecución de intereses estratégicos de género.

Palabras clave: Políticas de Igualdad, género, Planes de Igualdad, transversalidad, empoderamiento, gobierno local, Comunidad de Madrid.

\section{ABSTRACT}

This paper addresses the current gender equality policies in the municipalities of the Community of Madrid. The study focuses on the analysis of different aspects such as the

Fecha de recepción: noviembre 2012.

Fecha de aceptación: diciembre 2013. 
introduction and development of a Gender Department, the Equal Opportunities Plans, the Domestic Violence Programs or Work and Family Programs. Other initiatives to women are included in the analysis: workshops and cultural activities and training services for employees. The approach used in the study relates different geographical variables with the information about local gender policies, mainly to know how the last ones can contribute to the women empowerment and to the achievement of strategic gender needs.

Key words: Equality Policies, Gender, Equality Plans, Mainstreaming, Empowerment, Local government, Madrid Regional Community.

\section{INTRODUCCIÓN}

Uno de los cambios introducidos por el desarrollo de la democracia en España ha sido la atribución de amplias competencias al régimen local desde el punto de vista de servicio público, lo que implica una profunda transformación del concepto tradicional de beneficencia después de la recepción de su construcción dogmática elaborada por la Escuela de Burdeos. Aunque con significativos intentos durante el siglo XX, este cambio se manifiesta y consagra en el ámbito de las administraciones locales en la Constitución de 1978 (Título VIII, capítulos I y II) en donde se especifica que el municipio es una unidad territorial de acción política. Posteriormente, sus atribuciones y competencias se desarrollan en la Ley 7/1985, Reguladora de las Bases de Régimen Local, que especifica las competencias de actuación, convirtiendo la escala municipal en el marco de referencia para la promoción de determinadas actividades y la prestación de servicios públicos (FEMP, 2009b), en muchos casos relacionados con las necesidades cotidianas de las mujeres en su papel de cuidadoras del hogar y la familia.

En este contexto, nuestro trabajo pretende realizar un análisis de la implantación territorial de las políticas de género en los municipios de la Comunidad de Madrid, obteniendo una fotografía de su estado entre los meses de abril y julio de $2012^{1}$, siendo el objetivo fundamental determinar el grado de evolución e implantación de las mismas, valorando el tipo de políticas que se hacen y evaluando su relación con las necesidades de las mujeres y ciertos parámetros espaciales como el tamaño demográfico y los presupuestos. Se dispone de numerosos trabajos sobre este tema que parten de enfoques propios de la Sociología y la Ciencia Política, pero en España son escasísimos los que introducen el territorio como categoría de análisis, aparte de considerarlo como una circunscripción administrativa. Por tanto, es importante que desde la Geografía se realicen también investigaciones que completen lo aportado por otras disciplinas, aunque se considere que el enfoque transdisciplinar y la aplicación de la perspectiva de género son, igualmente, necesarios.

1 Este trabajo es el resultado parcial de investigaciones dentro del Grupo UCM, Relaciones de Género en el Mundo Contemporáneo: Una perspectiva interdiciplinar desde la Historia, La Geografía y el Derecho. Proyectos: «El género en las políticas locales», Programa de Creación y Consolidación de Grupos de Investigación de la Comunidad de Madrid 2009-2010, con la colaboración del BCSH; «El género en las políticas locales: análisis de casos en la Comunidad de Madrid», Programa de Creación y Consolidación de Grupos de Investigación de la Comunidad de Madrid, con la colaboración del BSCH (GR35/10-A), 2011. Directora de ambos proyectos: Dra. Gloria Nielfa Cristóbal. 
Este artículo se organiza en cuatro partes. En la primera se presenta el concepto de política local de igualdad, haciendo también referencia a los planteamientos teóricos y la bibliografía más relevante. En segundo lugar se abordará la metodología utilizada y el marco geográfico del análisis. Posteriormente, se pasará revista a los resultados más sobresalientes, haciendo una distinción entre aquellas políticas con un nivel de institucionalización alto, Concejalías de Igualdad y Planes de Igualdad, y las acciones concretas. En el último apartado se realizará una síntesis de los resultados, introduciendo también líneas de debate que se consideran esenciales.

\section{MARCO CONCEPTUAL DE LAS POLÍTICAS LOCALES DE IGUALDAD}

Las Políticas de Igualdad entre mujeres y hombres, en términos generales, consisten en la puesta en marcha de medidas de carácter corrector o compensatorio tendentes a eliminar aquellas discriminaciones por razón de sexo que limitan a mujeres y hombres la oportunidad de acceder y desarrollarse en igualdad en cualquier ámbito político, social, económico, cultural, afectivo, educativo, etc. Como parte de las medidas que se toman en Políticas de Igualdad están los planes o programas y, como forma última de concretarlos, las acciones o actividades (FEMP, 2006).

Desde la Ciencia Política y en relación con la incorporación de la perspectiva de género, es necesario identificar porqué y en qué momento éstas se incorporan a la agenda, como primer paso para valorar su evolución y grado de implantación. Aunque las reivindicaciones sobre la ciudadanía de las mujeres (derecho al voto) son más antiguas, es en los años sesenta del s. XX cuando los movimientos sociales representan la disconformidad con las estructuras y formas de ejercicio del poder mediante ciertos enfoques sociales, como el movimiento de mujeres, en constante presión para que su voz se escuchara (Bareiro, 1996). A la vez confluirán varias condiciones como una actitud favorable a la intervención por parte del Estado en temas sociales y la capacidad de éste para incorporar las diferentes voces sociales (Valiente, 1999). En el caso de España, tal como señalan María Bustelo, 2004 y Judith Astelarra, 2005, el movimiento de mujeres de los años sesenta y setenta formó parte de las fuerzas sociales y políticas que trajeron la democracia y el cambio social y sus reivindicaciones condujeron a la creación de organismos institucionales y a la implementación de políticas de igualdad. Por último, no se puede olvidar que una causa fundamental de la inclusión de políticas de género en el discurso y en la agenda política se debe a las directrices de la Unión Europea y a la adhesión de España a determinados tratados internacionales (Lombardo, 2002; Bustelo, op. cit.).

También ha de decirse que el papel que tiene el Estado en la superación de las desigualdades de género ha producido una importante controversia dentro del feminismo, donde «la práctica ha oscilado entre la adopción de una teoría liberal del Estado y una teoría 'de izquierdas' (marxista y postmarxista)» (Threlfall, 1990, en Bustelo op. cit.), criticándose asimismo el papel que éste puede tener como forma de reproducción de una jerarquía de dominación masculina (MacKinnon, 1989).

Se trata, en cualquier caso, de un proceso con numerosas negociaciones, de poderes en conflicto, de un largo asunto de carácter dialéctico, donde se producen avances y retrocesos, donde no pueden excluirse las tensiones entre diferentes definiciones del problema, entre diferentes racionalidades organizativas y de acción, y entre diversos baremos, perspectivas 
evaluadoras e ideologías (Baybrooke y Limdblom, 1963; Limdblom, 1990). En esta línea apuntan las ideas de Carol Bacchi (1999) y María Bustelo y Emanuela Lombardo (2004 y 2006) al señalar que la definición de los problemas políticos que llegan a la agenda no es una mera descripción de hechos objetivos, sino que tiende a ser una 'representación estratégica' que da relevancia a determinados asuntos, y que cada solución postulada contiene ya en sí misma una particular 'representación' de cuál es el problema y esto tiene implicaciones en el tipo de solución.

Una idea muy importante que subyace en algunos de los textos sobre la incorporación de la perspectiva de género a las políticas públicas es que las relaciones de género influyen en la articulación de las mismas y están influidas por dichas políticas (Peterson, 2005). Virginia Guzmán (1997) señala varias causas que todavía dificultan la construcción de una equidad de género, «algunas de ellas son el producto de la inercia de los sistemas cognoscitivos y valóricos, otras responden al rechazo de los hombres a ver afectados sus intereses en los espacios públicos y privados y otras tienen un sustrato más profundo. Se asocian al temor que generan los cambios en la identidad del otro al cuestionar la propia identidad, y a la incertidumbre sobre el propio sentido y consecuencias de las transformaciones en curso».

Con relación a la literatura sobre el tema que nos ocupa, en la esfera internacional hay obras muy destacadas como las de Bacchi, 1999; Sainsbury, 2000; Mazur, 2002, y la más reciente de Haussman y Sauer, 2007. Son muchos también los estudios que se centran en la introducción de la preocupación de género en las políticas europeas como los de Walby, 2004; Carbone, 2006; Bustelo y Lombardo, 2004 y 2006 y la producción del Instituto Europeo para la Equidad de Género (EIGE). En España también contamos con interesantes investigaciones sobre las políticas de igualdad en el ámbito internacional, estatal y en las Comunidades Autónomas como los de Sampedro, 1992; Bustelo, 2001 y 2004; Lombardo, 2004; Roldán, 2004; Valiente, 2005 y 2006; Astelarra, 2005; Rodríguez, 2010; Rodríguez y Navarro, 2012.

Desde el punto de vista de la óptica local se dispone asímismo de bibliografía relevante, aunque más escasa que en los casos anteriores, que varía en la extensión territorial del análisis, el enfoque disciplinario y la metodología. Resultan muy interesantes los materiales elaborados por el Área de igualdad de la Federación Española de Municipios y Provincias (2006, 2009) y, dentro del ámbito académico, los trabajos de Valiente, 1999; Lombardo, 2002; Gelambí, 2005 y Bouzas y Otero, 2011.

Celia Valiente (1999), con una metodología cualitativa, presenta la tipología de políticas locales de género imperante en ciertos municipios seleccionados de la Comunidad de Madrid, introduciendo, además, un interesante debate sobre las causas fundamentales de la implementación de este tipo de políticas, relacionándolas, solo en parte, con el signo político de las corporaciones municipales y mucho más con el volumen demográfico; esta autora también señala el escaso papel que han tenido las organizaciones feministas en la implantación de una agenda de género en la escala local. Emanuela Lombardo (2002) expone de forma integral las políticas de género de la provincia de Barcelona, haciendo una revisión de su implantación en la agenda en los diferentes niveles de la administración -desde el estatal al local- para a continuación identificar los diferentes tipos de acciones en la esfera municipal. Los resultados del reciente estudio de Bouzas y Otero (2011) se extraen a partir de un cuestionario realizado a los/as responsables de género de municipios de tamaño medio (198 casos); en él se señala que el elemento principal de la acción local en política de género es la 
elaboración de Programas y Planes de Igualdad, y que su existencia no implica su puesta en práctica, ya que es necesario evaluar la concreción y claridad de los objetivos, la existencia de mecanismos de coordinación entre las entidades municipales, la programación de actividades y tiempos, la disponibilidad de herramientas de evaluación y la dotación presupuestaria.

Los estudios de carácter geográfico sobre el ámbito municipal son, sin embargo, muy escasos debido, por un lado, a la ausencia de fuentes homologables para la investigación en un número amplio de entidades, y por otro, a que las políticas de igualdad en el ámbito local son un tema complejo donde intervienen distintos factores como la pluralidad de marcos de intervención (tamaño demográfico, organización de la corporación, presupuestos), la temporalidad (cada administración ha seguido una trayectoria distinta), la territorialidad, ya que las necesidades locales son muy dispares, y la variabilidad del escenario político (cambio de signo político de los consistorios).

\section{III. ÁMBITO DE ESTUDIO, METODOLOGÍA Y FUENTES}

La Comunidad de Madrid con sus casi 6,5 millones de habitantes en 2011 es la tercera Comunidad Autónoma más poblada del país y uno de los principales focos de actividad económica. Contabiliza uno de los ámbitos más urbanizados del Estado por el enorme peso y la gran extensión espacial del área metropolitana madrileña. A pesar de la escasa superficie de la Comunidad, la diversidad geográfica es importante, ya que a su gran conjunto metropolitano de 5,5 millones de personas se añade una extensa y creciente corona periurbana y unas cada vez más reducidas áreas donde las actividades tradicionales y el hábitat turísticoresidencial tienen aún una presencia territorial notable. Por otra parte, los contrastes sociales y económicos son importantes por la especialización funcional de los municipios y las características de sus residentes. En este proceso hay que destacar las diferencias sociales entre la almendra central y periferia Noroeste de la capital, donde viven mayoritariamente profesionales y puestos directivos en los servicios y la industria y las áreas del Sur, Este y Suroeste que sirven de residencia de obreros, más afectados por la crisis y con un deterioro de las condiciones laborales. A priori, parece razonable que las necesidades que presentan las mujeres residentes en las diferentes áreas identificadas deba manifestarse en el tipo de políticas de género; además, si se realizase un análisis histórico del signo político que han tenido los consistorios de estas zonas puede establecerse una relación entre nivel socioeconómico, partido gobernante e implantación de políticas de género, aunque no sea específicamente lo que ocupa esta investigación.

En esta línea, para evaluar el grado de implantación de las políticas de género se utilizaran categorías de análisis propias de los enfoques feministas, como la distinción entre roles de género y el concepto de empoderamiento, utilizadas reiteradamente en la literatura antes señalada. La valoración fundamental de los planes y acciones identificadas se realizará en función de su contribución a una de estas preguntas, en relación con los intereses de género: ¿a qué tipo de necesidades o aspiraciones contribuyen las acciones municipales?; ¿se trata de acciones encaminadas a satisfacer las necesidades prácticas de género o los intereses estratégicos?; ¿estas acciones contribuyen al empoderamiento?. Este tipo de análisis es propio de la identificación de proyectos de desarrollo en el Tercer Mundo dentro del enfoque GED (Gender and Development), formulado en sus inicios en los trabajos de Molineaux, 1985; 
Young, 1988 y Moser, 1989. Creemos que aunque se trata de enfoques destinados a valorar las acciones de los planes de desarrollo, su propuesta de análisis puede extrapolarse a cualquier iniciativa que tenga como objetivo la equidad de género.

La metodología utilizada para el análisis parte de la identificación de todo tipo de actividades de género, desde la creación de una concejalía específica hasta una acción determinada. Para ello se han seleccionado aquellos municipios con más volumen demográfico, descartando aquellos con menos de 5.000 habitantes; también se ha sustraído del análisis a la ciudad de Madrid, al tratarse de un municipio de magnitudes extraordinarias, difícilmente comparable con el resto. A partir de esta identificación y ante la falta de fuentes homogéneas, se ha optado por utilizar la información contenida en las Webs municipales destinadas específicamente a presentar acciones de género o para mujeres; se trata de una información referida a un momento concreto, «una radiografía que abarca cuatro meses en relación con la captura de los datos, abril- julio de 2012», siendo una de las características fundamentales de esta fuente, la evanescencia de la información, «lo que hoy aparece publicado, al día siguiente puede haberse retirado». La obtención de datos a partir de Webs institucionales tiene, a nuestro entender, algunas ventajas, como proponemos en las hipótesis de trabajo que a continuación presentamos:

1. En el momento actual, donde las políticas de género han entrado en la agenda desde un punto de vista del discurso, los agentes (concejales/as, alcaldes/as, personal técnico) presumiblemente intentarán hacer una buena comunicación de las acciones y actualmente, uno de los canales privilegiados de comunicación son las Webs municipales. Por tanto, esta fuente de información muestra qué se considera política de género en cada uno de los municipios y cuál es su estado de desarrollo, a la vez que se presenta gran parte de lo que se está realizando; puede ser que haya acciones que beneficien a las mujeres y no se identifiquen como tales, pero en este caso a nuestro juicio, no tienen por qué ser incluidas en el análisis, ya que no hay una identificación, ni política ni técnica, de la acción en su objetivo de contribuir a la equidad.

2. Siguiendo planteamientos de trabajos anteriores, los municipios con mayor volumen demográfico y presumiblemente, con mayor presupuesto tienen una capacidad superior de desarrollar políticas de género en tanto que disponen de una mayor capacidad institucional: medios económicos y humanos, recursos materiales (edificios), posibilidad de destinar un montante económico a políticas específicas y comunicación y puesta en valor de las acciones, donde Internet ocupa en la actualidad un lugar privilegiado. Creemos, no obstante, que la voluntad política puede jugar un papel importante al determinar lo que debe realizarse y el enfoque que se da a las acciones.

Una vez planteadas las hipótesis se ha procedido a la obtención de la información. En los trabajos de la FEMP (2006) se categorizan diferentes tipos de políticas, desde aquellas de carácter general, como los Planes de Igualdad hasta las acciones específicas. Así se ha creído necesario hacer una distinción entre aquellos instrumentos que suelen tener un mayor desarrollo institucional, y que algunos autores (Bouzas y Otero, 2011) consideran los elementos esenciales de la acción local -como las Concejalías de Igualdad y los Planes de Igualdad de Oportunidades- y las acciones concretas. En este sentido, se ha hecho una búsqueda temática en relación con el desarrollo de los primeros -Planes, Casas de la Mujer, Mesas Locales de 
Género, unidades específicas contra la violencia de género, entre otras-; en otros casos se ha extraído exhaustivamente la información que aparece en cada Web municipal, recopilando todas las acciones de los ayuntamientos con más de 12.000 habitantes y realizando un muestreo de aquellos de entre 12.000 y 8.000 habitantes. En total se ha extraído la información de 44 municipios, que suponen un volumen demográfico de 2.745 .704 personas $(43 \%$ de la población de la Comunidad). Una vez extraída la información se ha evaluado el nivel de institucionalización de la política de género, el tipo de actividad realizada según su formato (premios, talleres, jornadas conmemorativas) y el grado de trascendencia de la política en términos de consecución de la equidad de género (se trata de actividades que no cuestionan el sistema sexo/género, se mejora las necesidades prácticas, se contribuye a los intereses estratégicos de las mujeres (p.e. acceso al empleo), o se favorece el empoderamiento). Por último, una vez procesada toda la información se ha procedido a su cartografía y análisis mediante la puesta en relación con otras variables territoriales con el fin de visibilizar e interpretar su distribución.

\section{LAS POLÍTICAS MUNICIPALES DE IGUALDAD}

\section{Organismos municipales de igualdad}

El gobierno regional de la Comunidad de Madrid cuenta, dentro de la actual Consejería de Asuntos Sociales, con la Dirección General de la Mujer, organismo de gobierno y administración creado en 1989 que tiene como objetivo la consecución de la igualdad real y efectiva entre hombres y mujeres en los diferentes ámbitos de la vida política, económica y social. Entre sus atribuciones destacan la elaboración, implantación y evaluación de los Planes de Igualdad; impulsar la incorporación de la perspectiva de género en todas las normas, políticas, actuaciones, planes y estrategias de las instituciones; promover la plena participación política, social y económica de las mujeres; canalizar información y documentación, difundiendo estudios y datos; gestionar planes de formación y empleo; cooperar con organismos estatales y europeos de promoción de la igualdad de la mujer; gestionar el registro de asociaciones de mujeres y fomentar la prestación de servicios y programas a favor de las mujeres y en especial de aquellos colectivos especialmente vulnerables, como el de mujeres víctimas de violencia de género, que requieran una especial atención (Web Comunidad de Madrid, D. G. Mujer).

La responsabilidad sobre la Política de Igualdad en el ámbito local presenta una gran diversidad y complejidad. Una primera circunstancia radica en el término con el que se denomina en cada municipio al organismo encargado de su ejecución (Áreas, Delegaciones, Concejalías de Mujer). En líneas generales, se considera más eficaz que sea una Concejalía independiente (Concejalía de Igualdad o de Mujer), que un departamento, una delegación o un área dependiente de otra concejalía (Valiente, 1999; FEMP, 2006). Sin embargo, en el momento presente, son pocas las corporaciones que cuentan con una Concejalía de Mujer o de Igualdad independiente, además su número ha ido descendiendo desde 2010 por los cambios políticos y, sin duda, por efecto de la crisis económico-financiera (cuadro 1).

Con el gobierno socialista de Rodríguez Zapatero se creó el Ministerio de Igualdad a la vez que se impulsó la creación de las concejalías de igualdad en todo el territorio del Estado; 
la Ley Orgánica 3/2007, de 22 de marzo, para la igualdad efectiva de mujeres y hombres, supone la exigencia de una composición equilibrada en las listas electorales para municipios con 5.000 habitantes o más, sin embargo no se regula a cerca las figuras que pueden albergar una política municipal de género ni en lo referente al tipo de concejalías ni a los Planes de Igualdad, lo que sin duda es una carencia importante.

En cualquier caso, en la Comunidad de Madrid en 2010 y como resultado de una investigación anterior, contabilizamos treinta concejalías de mujer independientes entre los municipios de más de 5.000 habitantes. Sin embargo en julio de 2012, coincidiendo con la subida al poder de Mariano Rajoy (PP), desaparece el Ministerio de Igualdad y, paralelamente, muchas concejalías de igualdad son fusionadas con otras, de modo que en la actualidad sólo existen individualizadas en Alcalá de Henares, Alcorcón, Getafe, Griñón, Torres de la Alameda y San Sebastián de los Reyes, lo que representa solamente el 7,5\% de los municipios. Actualmente, lo más habitual es que el Área de Mujer esté asociada a otras concejalías, generalmente de Servicios Sociales, Cultura, Educación, Sanidad, aunque excepcionalmente hemos encontrado casos absolutamente incongruentes, estando unidas a otras áreas como Turismo, Industria, Medioambiente o Nuevas Tecnologías.

Cuadro 1

EVOLUCIÓN DE LA PRESENCIA DE CONCEJALIAS DE LA MUJER. MUNICIPIOS DE MÁS DE 5.000 HABITANTES EN LA COMUNIDAD DE MADRID (2008-2011 Y SITUACIÓN EN 2012)

\begin{tabular}{|l|r|r|r|r|}
\hline & \multicolumn{2}{|c|}{ 2008-2011 } & \multicolumn{2}{c|}{2012} \\
\cline { 2 - 5 } & TOTAL & \multicolumn{1}{|c|}{$\%$} & TOTAL & $\%$ \\
\hline Con Concejalías de Mujer/Igualdad individualizadas & 30 & 38,5 & 6 & 7.5 \\
\hline $\begin{array}{l}\text { Concejalía de Mujer agrupada con otros servicios, pero } \\
\text { con identificación temática de mujer o igualdad. }\end{array}$ & 30 & 38,5 & 53 & 67,9 \\
\hline $\begin{array}{l}\text { Sin mención expresa a igualdad o mujer. Se menciona solo } \\
\text { Servicios Sociales. }\end{array}$ & 16 & 20,5 & 19 & 24,4 \\
\hline Sin datos o sin Concejalía de Igualdad & 2 & 2,6 & 2 & 2,6 \\
\hline Total municipios & 78 & & 78 & \\
\hline
\end{tabular}

Fuente: Gago, C., Rodríguez J., Vidal Valiña, C. M. Consulta en las Webs municipales en los años 2010 y 2012. Los datos de 2010 proceden de una investigación anterior: Proyecto «El género en las políticas locales (2009-2010)», Programa de Creación y Consolidación de Grupos de Investigación de la Comunidad de Madrid.

Las figuras 1 y 2 indican, en líneas generales, como en el periodo de gobierno municipal anterior (2007-2011) los municipios de la periferia metropolitana, con un elevado volumen de población, tienen implantadas Concejalías de la Mujer, tanto a nivel independiente (fundamentalmente en el Sureste y Sur de la corona metropolitana), como integradas en concejalías con más funciones. Por su parte, los municipios inmediatos a la ciudad de Madrid por el Noroeste, tienen un escaso desarrollo de Concejalías de la Mujer, apreciándose solo presencia de aquellas de carácter social. 


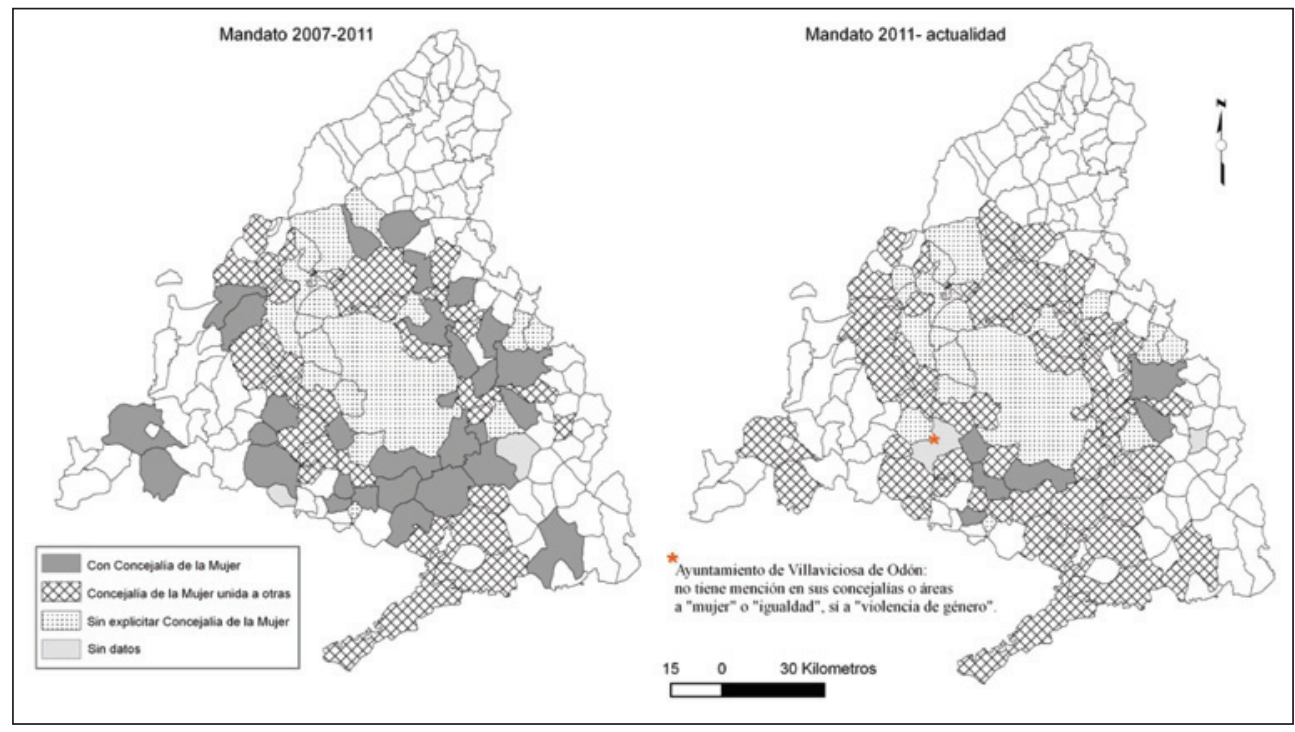

Fuente: investigación propia a partir de la consulta en las Webs municipales en ambos periodos de mandato.

Al mismo tiempo, el tamaño demográfico del municipio es una variable que condiciona el número de concejalías y las competencias de las mismas, aspecto que era muy evidente en el periodo 2007- 2011. Si las Concejalías de Igualdad o Mujer son más frecuentes en las corporaciones de los municipios grandes y medianos, no ocurre lo mismo en los más pequeños. En efecto, de los treinta municipios con Concejalía de Igualdad independiente de otras concejalías que existían en 2010, más del 50\% se encuentran en municipios mayores de 50.000 habitantes. En el momento actual, el 66\% de las mismas se encuentran en municipios de más de 100.000 habitantes, aun así, puede observarse cierto interés político por incluir instrumentos específicos para incorporar éstas en dos municipios con menos de 10.000 habitantes, en los casos de Griñón y Torres de la Alameda, con 9.546 y 7. 896 habitantes respectivamente (2012). Por el contrario, los municipios lejanos de la capital no cuentan con concejalías tan específicas, debido fundamentalmente a su reducida población y consiguiente escasa capacidad de gestión (Cuadro 2).

Por otro lado, la crisis económico-financiera en la que nos encontramos está reduciendo los presupuestos de todas las Administraciones Públicas, lo que sin duda está influyendo en la organización institucional de los entes locales. Aunque no disponemos de información a escala municipal, puede servir como referencia la Comunidad de Madrid. En ésta se ha producido una caída en la evolución del gasto propuesto para igualdad de género desde 2008 a 2012 con una reducción de más de 16 millones de euros, pasando de 44,8 millones a algo más de 27 millones en 2012. De los dos grandes capítulos que comprende el gasto de igualdad de género (Promoción e Igualdad de la Mujer y Acciones contra la Violencia de Género), el más afectado ha sido el primero, reservado a los convenios con las corporaciones locales para servicios sociales destinados a la promoción de 
la igualdad, que ha visto reducido el presupuesto un -13,8\% entre 2011 y 2012. De manera similar, este descenso del gasto está provocando que muchos municipios estén agrupando concejalías y no puedan actualizar sus Planes de Igualdad. No obstante, debe incidirse en que no tiene porqué estar relacionado, en principio, la fusión de concejalías o la escasez de recursos y el abandono del interés por la eliminación de las desigualdades de género.

Cuadro 2

CONCEJALÍAS DE MUJER O IGUALDAD EN LOS MUNICIPIOS DE LA COM. DE MADRID SEGÚN TAMAÑO DEL MUNICIPIO. MUN. DE MÁS DE 5.000 HABITANTES (AÑO 2012)

\begin{tabular}{|c|c|c|c|c|c|c|c|c|c|c|}
\hline & \multicolumn{2}{|c|}{$\begin{array}{l}5.000- \\
10.000\end{array}$} & \multicolumn{2}{|c|}{$\begin{array}{l}10.000- \\
20.000\end{array}$} & \multicolumn{2}{|c|}{$\begin{array}{c}20.000- \\
50.000\end{array}$} & \multicolumn{2}{|c|}{$\begin{array}{l}50.000- \\
100.000\end{array}$} & \multicolumn{2}{|c|}{$\begin{array}{c}\text { Más } \\
100.000\end{array}$} \\
\hline & Total & $\%$ & Total & $\%$ & Total & $\%$ & Total & $\%$ & Total & $\%$ \\
\hline $\begin{array}{l}\text { Con Concejalías de Mujer } \\
\text { individualizadas }\end{array}$ & 2 & 6,5 & & & & & & & 4 & 30 \\
\hline $\begin{array}{l}\text { Agrupadas con otros servicios, } \\
\text { pero con identificación } \\
\text { temática de mujer o igualdad. }\end{array}$ & 19 & 61,3 & 12 & 80 & 9 & 75,0 & 8 & 80,0 & 5 & 50 \\
\hline $\begin{array}{l}\text { Sin mención expresa a } \\
\text { igualdad o mujer. Se menciona } \\
\text { solo Servicios Sociales }\end{array}$ & 9 & 29,0 & 3 & 20 & 2 & 16,7 & 2 & 20,0 & 2 & 20 \\
\hline $\begin{array}{l}\text { Sin datos o sin Concejalía de } \\
\text { Igualdad }\end{array}$ & 1 & 3,2 & & & 1 & 9,3 & & & & \\
\hline Total municipios & 31 & 100 & 15 & 100 & 12 & 100 & 10 & 100 & 10 & 100 \\
\hline
\end{tabular}

Fuente: elaboración propia a partir de los datos de las Web de los Ayuntamientos de la Comunidad de Madrid. (Abril-Julio, 2012).

Continuando con la presentación de las acciones institucionalizadas a escala municipal cabe destacar dos más, la creación de Consejos o Mesas Sectoriales de Mujer y la de Centros, Casas o Estudios de Género (Figuras 3 y 4).

Los Consejos Sectoriales de la Mujer (figura 3) son órganos asesores y consultivos cuya finalidad es canalizar la participación de las ciudadanas y asociaciones de mujeres en los asuntos municipales relacionados. Están integrados por asociaciones de mujeres del municipio, sindicatos y partidos políticos con representación en el ayuntamiento. Dos de los primeros Consejos Municipales de este tipo creados en España (1989) pertenecen a la Comunidad de Madrid, los de Leganés y Getafe. Estos entes son una plasmación de la necesidad de construir democracias más participativas, estando inspirados en una serie de documentos internacionales. Por ejemplo, a finales de la década de los ochenta del siglo XX, la organización internacional Ciudades y Gobiernos Locales Unidos (CGLU) propuso la Declaración Mundial sobre las Mujeres en el Gobierno Local (1988). Posteriormente, en la Agenda 21 se recoge la importancia de que las autoridades locales pongan en marcha distintas actuaciones que faciliten la participación de las mujeres en los procesos municipales de adopción de decisiones, planificación y ejecución; des- 
taca asimismo el Programa Global sobre la Mujer en la Toma de Decisiones Locales, coordinado por el Consejo Europeo de Municipios y Regiones, que entre sus actividades ha desarrollado la Carta Europea para la Igualdad de mujeres y hombres en la vida local (2006) (FEMP, 2009a).

La distribución municipal de los Consejos de Mujer también revela la existencia de una elevada relación con el tamaño del municipio, tal es el caso de los municipios del Corredor del Henares, los situados en la autovía A-1 y todos los del Sur y Sureste. Por el contrario, los municipios con más de 40.000 habitantes del sector Oeste y Norte como Pozuelo de Alarcón, Boadilla del Monte y Colmenar Viejo no presentan consejo sectorial. Esta ausencia puede deberse a varias circunstancias; por un lado, se evidencia un falta de voluntad política por parte de los partidos que han ocupado los gobiernos municipales, por otro, puede ser que la especialización funcional, claramente residencial y terciaria de estos municipios pueda haber provocado que el tejido asociativo, sindical y político no sea tan numeroso como en los municipios del Eje del Henares. En este sentido, tal como señala la FEMP (2009a), las grandes diferencias intermunicipales en tamaño, órganos de gobierno, estructura de la corporación local, medios, relaciones con la administración regional y estatal, así como la historia e idiosincrasia de la implantación e impacto de la igualdad de oportunidades, la mayor o menor existencia de tejido asociativo femenino y otros muchos factores, influyen en el momento y en el modo más adecuado para la constitución de un Consejo Municipal de Mujer.

Figuras 3 y 4

LOCALIZACIÓN DE CONSEJOS O MESAS SECTORIALES DE MUJER Y DE CENTROS O CASAS DE LA MUJER
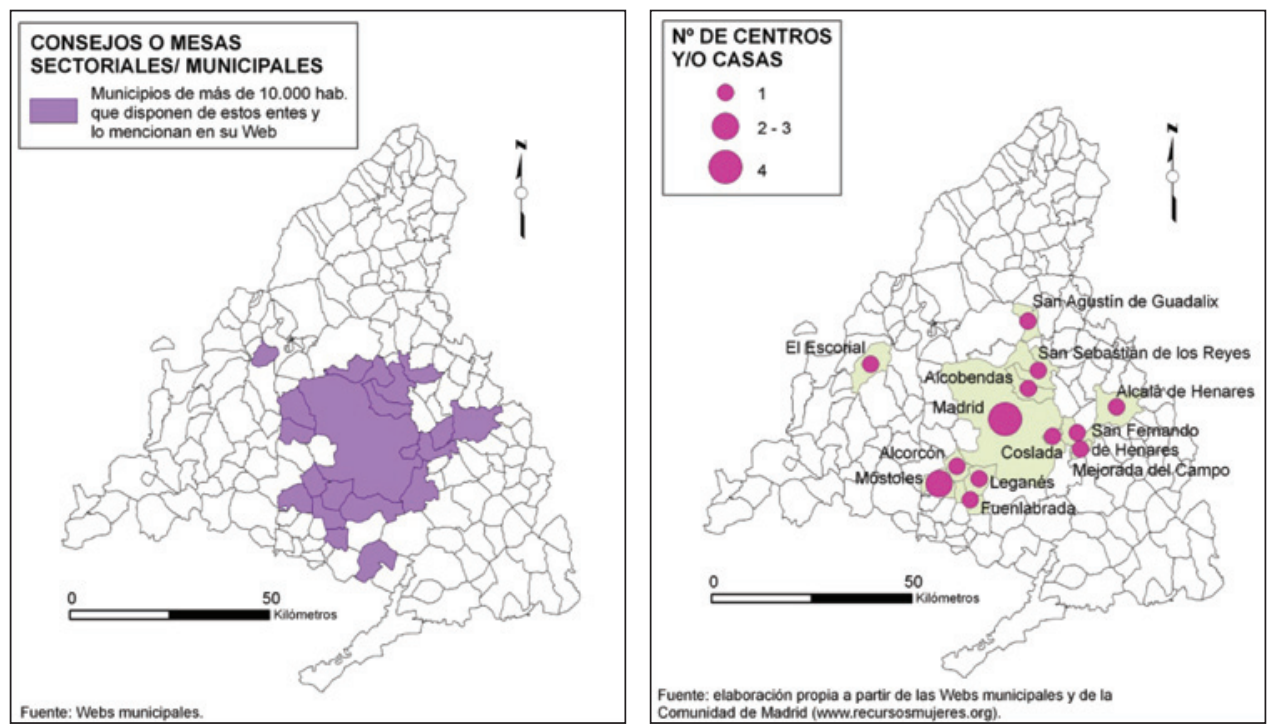

Las Casas de la Mujer representan el equipamiento de referencia donde residen los servicios municipales de promoción de la igualdad y las asociaciones relacionadas. De igual modo, sólo los municipios grandes han podido construir centros especializados para tratar temas específicos de las mujeres o de género, aunque la oferta de actividades que brindan es 
muy heterogénea. Gran parte de las actividades que se ofertan en las Casas de la Mujer son las que luego se publicitan en las Webs municipales, sirviendo de infraestructura básica para el desarrollo de talleres, conferencias, jornadas, cursos formativos, etc. La Casa de la Mujer de Móstoles es un caso singular en cuanto que además de albergar el Punto Municipal del Observatorio Regional de la Violencia de Género, oferta cursos de formación y talleres, y es sede de un Instituto de la Mujer entre cuyas dependencias se encuentra el Centro de Información y Documentación, dedicado a temáticas y estudios de género.

Dentro de los organismos de igualdad de ámbito administrativo superior no deben ser olvidados en la Comunidad de Madrid los Puntos Municipales del Observatorio Regional de la Violencia de Género (PMORVG). En efecto, la importancia que ha alcanzado este problema en España llevó al poder judicial a redactar la Ley Orgánica 1/2004, de Medidas de Protección Integral contra la Violencia de Género; en el caso de la Comunidad de Madrid se redactó posteriormente la Ley 5/2005 de diciembre, Integral contra la Violencia de Género, destinada a combatir y prevenir esta lacra en el ámbito de la región; ésta, en el Título II, hace referencia a la colaboración con los municipios para la creación de la Red de Puntos Municipales que, coordinados por la Dirección General de la Mujer se definen como espacios de atención especializada, en el que se ofrecen servicios de carácter gratuito orientados tanto a atender a mujeres víctimas y a sus hijos e hijas, como a prevenir y sensibilizar sobre este tipo de violencia. Entre sus cometidos se encuentran ofrecer acompañamiento y atención integral en todo el proceso de protección de la mujer y de superación de las secuelas.

Como se observa en la figura 5, los PMORVG tienen una representación territorial extensa. Así, la Comunidad de Madrid tiene 50 Puntos distribuidos entre 34 ayuntamientos y 14 mancomunidades. Aquellos municipios de más de 10.000 habitantes cuentan con un centro para sí mismos, aquellos otros que tienen una población menor a 10.000 habitantes tienen un Punto en la sede de su Mancomunidad de Servicios Sociales. Los municipios que no se encuentran en alguno de los supuestos anteriores, disponen de más de un Punto, es el caso de Madrid.

LOCALIZACIÓN DE LOS PUNTOS MUNICIPALES DEL OBSERVATORIO REGIONAL DE VIOLENCIA DE GÉNERO

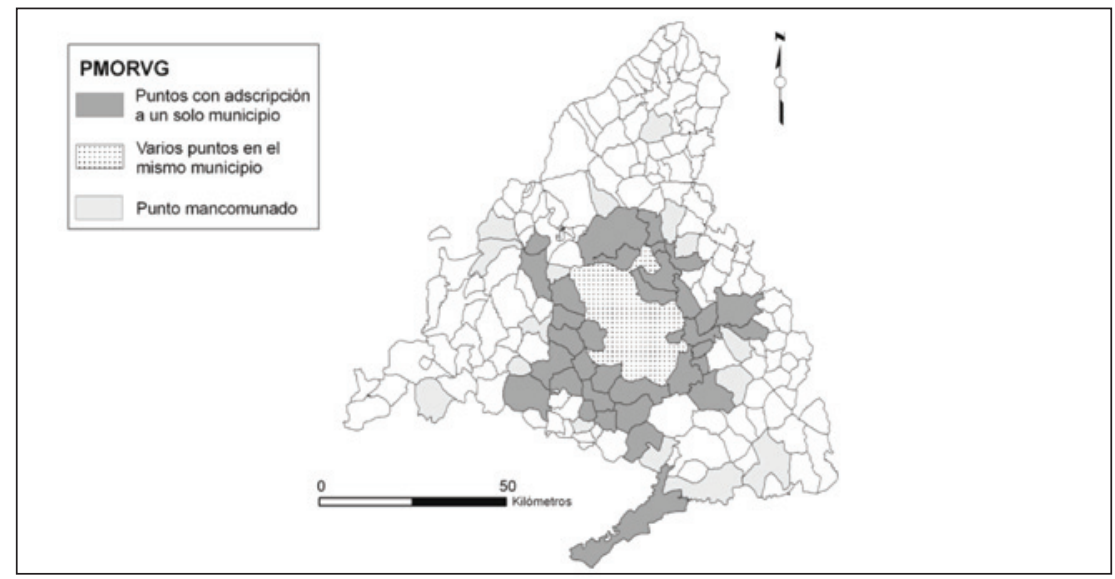

Fuente: elaboración propia a partir de datos de la Comunidad de Madrid. www.recursosmujeres.org 


\section{Las políticas específicas de igualdad}

Este apartado está dedicado a presentar las diferentes acciones y actividades que se desarrollan en la escala municipal. Para su mejor comprensión, se han dividido entre aquellas presumiblemente de carácter integral, como son los Planes de Igualdad, y las acciones concretas que han sido identificadas en la investigación.

\subsection{Planes de Igualdad de Oportunidades entre mujeres y hombres}

A lo largo de los últimos veinte años, las políticas de igualdad de género a nivel local han ido adquiriendo un protagonismo propio. Éstas se han articulado a través de los Planes de Igualdad de género, que incluyen los objetivos a cumplir y las actuaciones a desarrollar por parte de todos los agentes implicados, con la finalidad de producir cambios en la realidad local. Los planes deben aprobarse por el pleno del ayuntamiento y suelen tener duración cuatrienal, coincidiendo con el mandato municipal. En un principio, éstos fueron instrumentos políticos que tomaron como modelo los programas de acción comunitaria de la Comisión Europea definidos como: «un tipo particular de políticas de género cuyo propósito es abordar las distintas dimensiones de la discriminación: las estructuras que se derivan de la división sexual del trabajo y de la posición de las mujeres en la familia, en el mercado y en la vida política y las de carácter cultural derivadas de la imposición de determinados patrones de interpretación y de comunicación de la realidad social que se brinda a las mujeres» (Martínez y Escapa, 2008: 285).

Los actuales Planes de Igualdad deben ajustarse a los planteamientos y objetivos perseguidos por la Ley Orgánica 3/2007 (LOI). Para su aplicación, el Art ${ }^{\circ} .17$ establece la elaboración de un Plan Estratégico que concrete los objetivos, ámbitos y medidas de actuación en los que los poderes públicos han de centrar sus actuaciones. Como consecuencia, el Gobierno del Estado aprobó el Plan Estratégico de Igualdad de Oportunidades (2008-2011); con la misma pauta y en el ámbito de la Comunidad de Madrid, se han desarrollado la «Estrategia para la Igualdad de Oportunidades entre mujeres y hombres de la ciudad de Madrid (20112015)» y la «Estrategia Municipal para la Igualdad de oportunidades de Móstoles». Entre las líneas maestras de estos documentos destacan dos: la incorporación de la transversalidad (enfoque integrado de género) en la gestión municipal y el avance hacia la igualdad real entre hombres y mujeres a través de la sensibilización de la población y el empoderamiento. Consecuentemente, tras la trayectoria seguida y la experiencia acumulada en la implantación y el desarrollo de los planes anteriores, los actuales se plantean nuevos retos en el proceso de consecución de la igualdad, incluyendo algunas de las medidas reguladas en los anteriores, a la vez que incorporan otras distintas por la necesidad de realizar una planificación global que integre la transversalidad o mainstreaming.

Desde el punto de vista territorial (figuras 6 y 7) no todas las corporaciones locales tienen sus propios Planes de Igualdad. De los 79 municipios con más de 5.000 habitantes, solo 52 han redactado alguno y de éstos se encontraban en vigor en 2011 casi la mitad (25). Geográficamente es Madrid Capital, junto con los municipios del Área Metropolitana los que tienen mayoritariamente implantados Planes de Igualdad, con la excepción de Alcobendas y Tres Cantos cuyas Webs municipales no aportan su existencia, si bien desarrollan 
programas y acciones. Por el contrario, la planificación de género es menos frecuente en las administraciones locales más modestas que suelen coincidir con las zonas rurales, en las que sin embargo, los estereotipos sexistas están más profundamente arraigados. Un aspecto reseñable es que ante el pequeño tamaño de muchos municipios, algunos se han fusionado en Mancomunidades Intermunicipales de Servicios Sociales ${ }^{2}$; de todas estas, cinco cuentan con Planes de Igualdad en vigencia: Mancomunidad de TAHM, Este de Madrid- MISSEM, Las Vegas, Vega del Guadalix y Los Pinares.

Un rasgo interesante respecto a los planes es el número de formulaciones que han realizado y su grado de actualización. Entre los municipios que han elaborado un mayor número de planes se encuentran los siguientes: Parla, Fuenlabrada, Torrejón de Ardoz, Alcalá de Henares, Arganda del Rey, y fuera del Área Metropolitana, Aranjuez, Soto del Real y El Escorial. La actualización de estos documentos es también diversa, aunque como puede observarse en el mapa (fig. 6) un número considerable de municipios no disponen de un texto actualizado, en lo que sin duda confluyen una vez más intereses políticos y restricciones presupuestarias.

En cuanto a los contenidos de los Planes, aparte de incorporar la caracterización demográfica, económica y social de las entidades locales casi todos evalúan los planes anteriores. Frente a lo detectado por Celia Valiente (1999) en su estudio de la Comunidad de Madrid, en la actualidad la mayoría parten del análisis de los resultados obtenidos en la evaluación del anterior plan, y ésta proporciona la información necesaria para saber cuáles son los puntos fuertes y débiles en el tratamiento de la igualdad de cara a plantear las áreas y actuaciones más adecuadas. Por otro lado, como ha señalado Bustelo (2004), los Planes de Igualdad presentan una serie de debilidades entre las cuales podemos destacar tres: a) la mayoría de los planes presentan contenidos similares ya que tienen que tener en cuenta las directrices marcadas por la normativa europea para su elaboración, aunque con las adaptaciones necesarias para responder a las condiciones y necesidades específicas en su respectivos municipios; b) no todos los organismos de igualdad de los entes locales han implicado en el proceso de elaboración a los diferentes grupos de mujeres (asociaciones, sindicatos, empresarias...) como es el caso de Parla o Móstoles; en otros casos, los organismos de igualdad encargan la elaboración del plan a empresas consultoras como en Collado Villalba o en la Mancomunidad de la Vega del Guadalix, con el consiguiente riesgo de carencia de participación social; c) los organismos de igualdad y el personal técnico deben convencer a otras concejalías para asumir y ejecutar unos objetivos que inicialmente no consideran como suyos.

2 Municipios incluidos en las diferentes Mancomunidades. Mancomunidad Intermunicipal de Servicios Sociales TAHM: Torrelodones, Hoyo de Manzanares, Alpedrete y Moralzarzal; Mancomunidad Intermunicipal de S.S. del Este de Madrid, MISSEM: Ambite, Campo Real, Loeches, Olmeda de las Fuentes, Pozuelo del Rey y Villar del Olmo; Manconunidad de Las Vegas: Chinchón, Ciempozuelos, Morata de Tajuña, San Martín de la Vega, Titulcia y Villaconejos; Mancomunidad Vega del Guadalix: Guadalix de la Sierra, El Molar, Pedrezuela; Mancomunidad Los Pinares: Aldea del Fresno, Cadalso de los Vidrios, Cenicientos, Chapinería, Colmenar de Arroyo, Navas del Rey, Pelayos de la Presa, Rozas de Puerto Real, San Martín de Valdeiglesias y Villa del Prado. 


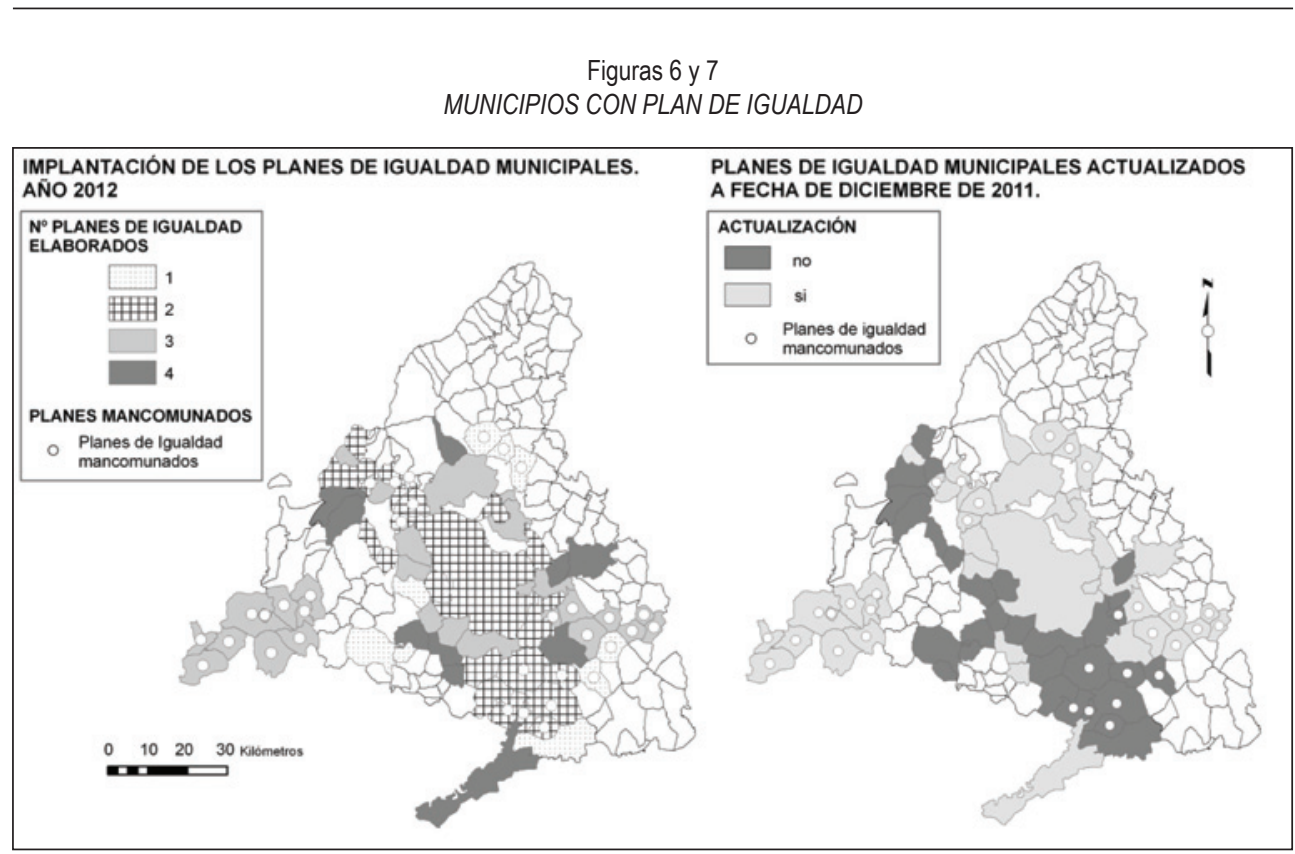

Fuente: elaboración propia a partir de las Webs municipales o de las Mancomunidades.

Al mismo tiempo, todos los planes plantean unos principios rectores en los que se fundamentan cada uno de los objetivos marcados y las acciones a desarrollar para la consecución de los mismos, constituyendo el marco necesario donde se inscriben las políticas de igualdad de oportunidades entre mujeres y hombres llevadas a cabo. En los planes analizados (un total de 22) los principios rectores suelen coincidir con cuatro: transversalidad, participación, diversidad y modernidad. En el caso del IV Plan la Igualdad entre Mujeres y Hombres de Parla (2009-2012) a los principios rectores ya señalados se incorporan además, el compromiso político, el empoderamiento y la innovación. Los organismos implicados en la transversalidad deben ser todas las concejalías junto con la colaboración en su desarrollo de asociaciones de mujeres y el Consejo Social de la Mujer.

En cuanto a la estructura y contenido de los planes estudiados, el número de «Áreas generales» o «Metas» varía entre 4 y 11, desarrolladas en objetivos que impulsan las acciones necesarias para lograrlos. Para su comprensión se ha procedido a una clasificación temática, identificando ocho áreas comunes que han sido objeto de tratamiento en la mayoría de los planes (cuadro 3). Como se desprende de esta información, de los 22 planes analizados, hay dos áreas que constituyen un punto común en todos: la conciliación de la vida laboral y familiar y la erradicación de la violencia de género. Además, encontramos que el área de educación, cultura, deporte y medios de comunicación, seguida muy de cerca por las de Transversalidad (introducción de la perspectiva de género en las políticas públicas) y Salud y calidad de vida están ampliamente desarrolladas; de manera más puntual los planes recogen metas en temas de participación de las mujeres en la vida ciudadana, trabajo e inserción laboral y cooperación. 
Cuadro 3

AREAS DE LOS PLANES DE IGUALDAD DE OPORTUNIDADES EN LOS MUNICIPIOS DE LA COMUNIDAD DE MADRID

\begin{tabular}{|l|r|r|}
\hline Áreas & $\mathbf{N}^{\mathbf{0}}$ de planes & Porcentaje \\
\hline $\begin{array}{l}\text { Introducción de la perspectiva de género en las políticas públicas } \\
\text { (Transversalidad) }\end{array}$ & 16 & 72,73 \\
\hline Trabajo e inserción laboral & 11 & 50,00 \\
\hline Conciliación de la vida laboral y familiar & 22 & 100,00 \\
\hline Violencia de género & 22 & 100,00 \\
\hline Educación, cultura, deporte y medios de comunicación & 17 & 77,27 \\
\hline Salud y calidad de vida & 14 & 63,64 \\
\hline Participación de las mujeres en la vida ciudadana & 11 & 50,00 \\
\hline Cooperación & 3 & 13,64 \\
\hline
\end{tabular}

Fuente: elaboración propia a partir de los Planes de Igualdad Municipales ( $\mathrm{n}^{\mathrm{o}}$ de planes consultados: 22)

\subsection{Acciones}

La información analizada en este apartado procede de la recopilación de todas las actividades y/o programas de las Web de género o mujer de los 44 municipios considerados, que posteriormente ha sido clasificada y cuantificada en relación con la presencia de las actividades en cada uno de los municipios. Parece, a priori, sensato pensar que la gran mayoría de las actividades que ocupan las Webs están en casi total relación con la planificación propuesta en los Planes de Municipales de Igualdad. No obstante, muy pocos presentan una programación o temporalización de las actividades, por lo que resulta casi imposible valorar la correspondencia entre lo programado en ellos y lo realizado mediante las distintas acciones.

De la extracción exhaustiva de la información se ha realizado un inventario que posteriormente se ha clasificado con un doble criterio. Por un lado, se han utilizado categorías que reiteradamente aparecen en las Webs, como por ejemplo la conmemoración del Día Internacional de la Mujer; por otro, se ha clasificado la información en función de su contribución a la consecución de la equidad de género. Además, las acciones se han calificado, siempre que ha sido posible, en función de los formatos en los que se producen: conferencias, premios, talleres, actividades reivindicativas...

Con respecto a la clasificación de las actividades identificadas ha de hacerse una matización importante. Desde nuestro punto de vista gran parte de las actividades deberían marcar en su formulación los objetivos de género a alcanzar. En nuestro análisis, el objetivo se ha extraído del enunciado de la actividad, y puede que enunciados que presumiblemente obedecen a una política de género, luego no tengan un desarrollo conveniente, mientras que en otros casos actividades que presumiblemente reproducen los papeles tradicionales femeninos se convierten, por el encuentro e intercambio de experiencias entre mujeres en espacios de empoderamiento, idea que ya señaló Valiente (1999). La evaluación, así como la clasifica- 
ción resulta, por lo tanto, difícil y debe tomarse como una aproximación a la realidad, de ningún modo de forma absolutamente categórica, en tanto que tampoco es posible valorar mediante el análisis de las Webs el seguimiento de la actividad por parte del grupo meta, ni el volumen ni la intensidad en que se realizan las actividades.

Los resultados (cuadro 4) muestran tres grupos de actividades mayoritariamente realizadas: conmemoración del Día Internacional de la Mujer (97,7\%), publicitación de actividades contra la violencia de género $(93,2 \%)$ y la realización de talleres o «cursillos para mujeres». Con respecto al resto de actividades identificadas, en dos casos más, actividades dirigidas a la conciliación de la vida familiar y laboral (65\%) y aquellas destinadas a la formación para la igualdad en centros educativos, sobrepasa su implantación el $50 \%$ de los ayuntamientos. Las actividades, a nuestro juicio, muy «emprendedoras» en la consecución de la equidad como las políticas de promoción del empleo para mujeres, que de forma directa favorecen los intereses estratégicos de género, tienen una presencia menor (38,8\% de los municipios). Con respecto a la evolución de todas estas acciones, se constata que muchas de ellas fueron identificadas en trabajos anteriores (Valiente, op. cit.), teniendo una trayectoria temporal amplia, mientras que otras han adquirido mayor desarrollo, como las actividades de conciliación, el trabajo en centros educativos y fundamentalmente los talleres relacionados con el empoderamiento, la autoestima y el pensamiento feminista. Destaca también el interés por informar sobre los recursos disponibles contra la violencia de género.

El Día Internacional de la Mujer se conmemora en casi todos los municipios, aunque con una interpretación de las actividades muy variada. Algunos realizan simplemente una actividad de carácter testimonial, sin embargo, en otros su extensión puede variar desde una sola jornada, una semana, incluso el mes de marzo al completo. En cuanto al tipo de acciones, son prácticamente similares a las que se realizan durante el resto del año, como talleres, charlas y conferencias; otras más concretas incluyen programaciones de carácter reivindicativo: lectura de un manifiesto, una declaración institucional, carreras populares, concentraciones de sensibilización, marchas, etc. Además la conmemoración de este día destaca con respecto a muchas otras actividades programadas anualmente por su carácter festivo y lúdico.

Cuadro 4

ACTIVIDADES DE GÉNERO IDENTIFICADAS EN LAS WEB MUNICIPALES RESUMEN DE ACTIVIDADES. NÚMERO DE MUNICIPIOS QUE LAS OFERTAN

\begin{tabular}{|c|c|c|}
\hline & Total & $\%$ \\
\hline \multicolumn{3}{|c|}{$\begin{array}{l}\text { DE CARÁCTER GENERAL: SENSIBILIZACIÓN, VIOLENCIA, FORMACIÓN EN TEMAS } \\
\text { DE IGUALDAD }\end{array}$} \\
\hline Celebración del Día Internacional de la Mujer & 43 & 97,7 \\
\hline Publicitación de actividades contra la violencia de género & 41 & 93,2 \\
\hline Talleres para mujeres & 38 & 86,4 \\
\hline Actividades de formación y sensibilización en centros educativos & 23 & 52,3 \\
\hline
\end{tabular}




\begin{tabular}{|c|c|c|}
\hline & Total & $\%$ \\
\hline \multicolumn{3}{|l|}{ CONCILIACIÓN: NECESIDADES PRÁCTICAS } \\
\hline Total municipios con actividades de conciliación & 29 & 65,1 \\
\hline Actividades de sensibilización en relación con la conciliación & 18 & 40,9 \\
\hline Iniciativa empresarial & 11 & 25,0 \\
\hline Puesta en valor de recursos municipales para la conciliación & 8 & 18,2 \\
\hline $\begin{array}{r}\text { Publicitación en la Web de actividades de apoyo a las mujeres en sus necesidades } \\
\text { prácticas }\end{array}$ & 16 & 37,3 \\
\hline Bancos del tiempo & 5 & 11,3 \\
\hline \multicolumn{3}{|c|}{ CAPACITACIÓN Y FORMACIÓN PARA EL EMPLEO: INTERESES ESTRATÉGICOS } \\
\hline Formación y empleo & 17 & 38,6 \\
\hline Promoción de mujeres empresarias & 11 & 25,0 \\
\hline
\end{tabular}

Fuente: investigación a partir de la información que aparece en la Web institucional de cada uno de los municipios.

En relación con las acciones en contra de la violencia de género, casi todos los municipios presentan en sus Webs $(93,2 \%)$ alguna indicación sobre los servicios que ofrecen, debido en parte a la sensibilización social que existe sobre el tema. Mayoritariamente éstas reflejan la posibilidad de acudir al PMORVG que, como se ha señalado, es una iniciativa de carácter autonómico aunque se desarrolle en el ámbito local. El análisis de las políticas municipales contra la violencia de género excede, con mucho, el propósito de esta investigación, pues requiere de planteamientos teóricos y metodologías propias. No obstante, deben destacarse algunas acciones propiamente municipales como las Mesas Municipales contra la violencia de género, las unidades especiales de las policías locales y los servicios integrales de atención a mujeres, de iniciativa local.

El tercer grupo de actividades identificadas según el número de municipios que las desarrollan son los talleres, tratándose de una práctica con mucha implantación $(86,4 \%)$ pero muy heterogénea y de propósitos muy variados (figura 8). Algunos talleres reproducen roles femeninos tradicionales, otros están dedicados a ocupar el tiempo de ocio (p.e. manualidades), mientras que algunos contemplan específicamente la formación en temas feministas y de género. En este sentido es importante señalar que aquellos relacionados con la psicología, destinados básicamente trabajar los conceptos de autoestima, autoconocimiento, crecimiento y comunicación personal, relajación, autodefensa, etc., tienen implantación en un número alto de municipios; también destacan los talleres destinados a la formación en igualdad y género y en tercer lugar, aquellos en relación con la creatividad, de índole artística y literaria. 
Respecto a la valoración y el impacto que tienen los talleres, poco se menciona en las Webs a parte que «las plazas se han agotado por completo» o que «la oferta supera la demanda». Probablemente deba existir documentación interna en los ayuntamientos que valore el número de plazas ofertadas y el seguimiento realizado; se hace necesario también la obtención de evidencias más cualitativas, como el impacto de aquellos talleres con una mayor componente de género. Por otro lado, parece probable que la oferta en relación con talleres de corte tradicional como manualidades o salud de la mujer, destinados a ocupar el tiempo de ocio, tengan una implantación mayor, pero que sean desarrollados desde otras áreas de gobierno.

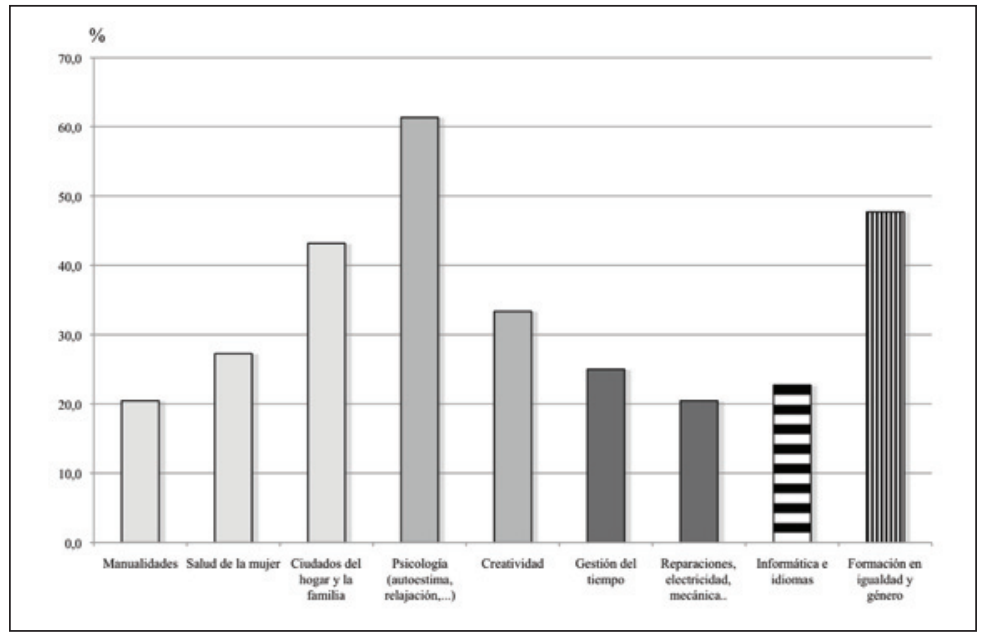

Fuente: investigación en las Webs municipales. 44 municipios analizados.

Entre las actividades identificadas también destacan aquellas destinadas a la comunidad educativa, y un 52,3\% de municipios las presentan en sus Webs. Entre sus características puede señalarse que se trata de talleres o clases participativas, impartidos a estudiantes de Educación Primaria o Secundaria, fundamentalmente en 3 y $4^{\circ}$ de la ESO, aunque pueden incluirse también en otras fases educativas; dentro de este tipo de acciones un escaso número de municipios, además, ofrece propuestas para las AMPAS y el profesorado. Este tipo de iniciativas deben valorarse, a priori, muy positivamente en cuanto que la educación es uno de los medios más importantes para lograr la equidad; la evaluación de la acción se hace, no obstante, difícil porque es necesario indicadores de carácter cualitativo y un seguimiento a largo plazo. Sin embargo, sería relativamente factible obtener indicadores sobre el número de centros y estudiantes que reciben la acción, cifras que, al menos, no se hacen públicas. Una excepción, que sin duda debe resaltarse, es un estudio sobre talleres contra la violencia de género elaborado por el Consistorio de Fuenlabrada, donde se proporcionan cifras de los estudiantes que han recibido la actividad, «un total de 1.300 a 1.850 adolescentes cada año» (cuadro 5), lo que puede considerarse un número notable, teniendo en cuenta la cohorte total. 
Cuadro 5

ESTUDIANTES QUE RECIBEN FORMACIÓN EN TEMAS DE VIOLENCIA DE GÉNERO. AYUNTAMIENTO DE FUENLABRADA

\begin{tabular}{|l|r|r|r|r|}
\hline & \multicolumn{1}{|c|}{ Curso 05/06 } & \multicolumn{1}{c|}{ Curso 06/07 } & \multicolumn{1}{c|}{ Curso 07/08 } & \multicolumn{1}{c|}{ Curso 08/09 } \\
\hline $\mathrm{N}^{\mathbf{0}}$ de centros & 7 & 10 & 9 & 9 \\
\hline $\mathrm{N}^{\mathbf{o}}$ de aulas & 63 & 74 & 65 & 53 \\
\hline Total alumnas/os & 1.575 & 1.850 & 1.625 & 1.325 \\
\hline
\end{tabular}

Fuente: Fundación Mujeres (2009): Educar para prevenir la Violencia de Género, Concejalía de Igualdad y Empleo, Ayuntamiento de Fuenlabrada.

Respecto a la conciliación, existen diferentes trabajos sobre España y Europa que analizan el tipo de discurso presente en los documentos elaborados (Peterson, 2005; Bustelo y Lombardo, 2006); éstos coinciden en que este tipo de políticas tienden a dar prioridad a soluciones dirigidas a hacer factible el combinar las responsabilidades del ámbito familiar y del ámbito laboral frente a aquellas dirigidas a una distribución más igual de las responsabilidades entre sexos y que por tanto, en el discurso se representa el problema de la conciliación como un «problema solo de mujeres». También se indica que en numerosas ocasiones las políticas no cuestionan los roles de género, sino que se reproducen las construcciones del «varón sustentador» y de la «mujer cuidadora».

En cualquier caso, desde el punto de vista de los intereses prácticos de género la conciliación es una premisa indispensable para que las mujeres puedan realizar una actividad remunerada; asimismo, el ámbito local juega un papel privilegiado al ser la unidad básica de dotación de servicios públicos como guarderías, centros educativos, cuidado de personas dependientes, residencias para la Tercera Edad, etc. La conciliación, como prioridad política, tiene una presencia media en los 44 municipios analizados, concretamente en un total de 29 $(65,9 \%)$. Las actividades en relación con este tema han sido catalogadas en cinco tipos para su mejor análisis:

1. Actividades de sensibilización y formación en temas de conciliación (talleres, reuniones, jornadas): 40,9\% de la muestra.

2. Actividades de conciliación en relación con el empresariado local (premios, jornadas técnicas, formación a la empresa, sellos de calidad en relación con la conciliación): $25 \%$.

3. Puesta en valor de recursos municipales para la conciliación (elaboración de catálogos de los recursos municipales disponibles): $18,2 \%$

4. Publicitación en la Web de actividades de apoyo a las mujeres en sus necesidades prácticas de género (cuidado de niños/as, personas dependientes y personas ancianas): 37,3\%.

5. Bancos del tiempo: $11,3 \%$.

El último grupo de acciones registrado en nuestro análisis está en relación con la promoción y acceso al empleo. Este tipo de políticas es, sin duda, relevante como intento de favorecer el acceso de las mujeres al trabajo remunerado, y así obtener una posición de género más equitativa (interés estratégico). Ha de decirse que los municipios apenas gozan de competencias en relación con la promoción del empleo, en manos del Estado y las Comunidades Autónomas, y que en gran medida ésta depende de una planificación 
económica que, sin duda, se escapa del ámbito municipal. En algunos casos se ha comprobado cómo aunque las Webs presentan actividades de fomento del empleo, el papel del ayuntamiento se limita a la cesión de instalaciones, mientras que son el INEM, el Instituto de la Mujer o la Dirección General de la Mujer quienes proponen y gestionan los cursos de Orientación y Formación Ocupacional. Los datos del análisis han desvelado que las acciones municipales de formación de mujeres para el empleo tienen una implantación geográfica escasa, únicamente en 17 municipios $(38,7 \%)$, y que éstas se recortan hasta un total de $11(25 \%)$, en lo referente a la promoción del autoempleo y el apoyo a mujeres empresarias.

Entre este tipo de actividades se encuentran las siguientes: foros o talleres de búsqueda activa de empleo -donde se proponen, entre otras temáticas, la creación de redes y la capacitación de las mujeres a la hora de realizar la entrevista de trabajo-, cursos de formación ocupacional (jardinería, auxiliar de actividades extraescolares, informática, diseño gráfico, etc.), cursos de gestión del tiempo y actividades de orientación laboral. La información disponible en lo que se refiere al fomento del empleo femenino no permite, en ningún caso, valorar la magnitud en términos de mujeres que solicitan los servicios ni la efectividad de los mismos. En cuanto a las actividades destinadas a mujeres empresarias y/o emprendedoras, los servicios que se prestan están encaminados al asesoramiento para establecer un negocio: ayudas disponibles, gestión empresarial, trámites jurídicos y acompañamiento en la creación y consolidación de empresas de mujeres, en algún caso, en sectores con poca presencia femenina.

Una vez presentadas las actividades de género desarrolladas en los municipios de la Comunidad de Madrid parece necesario insistir en su heterogeneidad en relación tanto a la tipología de acciones como a la implantación geográfica. Resulta muy positivo que algunos municipios presenten un abanico de actividades numeroso y variado que aborda casi todas las facetas analizadas, tanto desde el punto de vista del formato en que se realizan las acciones (talleres, jornadas conmemorativas, premios, charlas, actividades lúdicas...) como en el enfoque que se da (sensibilización y concienciación, empoderamiento, conciliación y fomento del empleo). Sin embargo, la evaluación de las mismas resulta, a nuestro juicio, bastante complicada en cuanto que no hay datos disponibles, a excepción de las acciones contra la violencia de género, ni de los grupos meta, ni de las usuarias, ni mucho menos del impacto que pueden tener ciertas políticas.

No obstante, uno de los objetivos propuestos en la investigación fue valorar las posibles relaciones entre la implantación de acciones de género y diferentes componentes territoriales. Para ello se ha recurrido una técnica de evaluación de carácter cuantitativo mediante puntuaciones ponderadas ${ }^{3}$, que han sido determinadas con carácter experimental, según la

3 Las técnicas de evaluación mediante puntuaciones ponderadas ha sido desarrollada en el ámbito de la Geografía con el propósito de medir variables territoriales, como la jerarquía espacial o la determinación de indicadores sintéticos de género (Sabaté et al. 2008). Este método igualmente puede aplicarse a la evaluación de determinados indicadores de carácter social. La puntuación de cada municipio para cada variable (Vn) de la dimensión considerada, se ha calculado como la presencia de la actividad (1), entre el sumatorio de municipios que presentan esa actividad $\left(\mathrm{Vn}=1 / \sum_{i=1}^{n} x\right)$; cada dimensión resulta del sumatorio ponderado de las diferentes variables que la componen $(100 \%)$. Los criterios experimentales de ponderación, que deben considerarse como una primera aproximación, y que se contrastarán con un papel de expertas en la siguiente fase de la investigación, han sido los siguientes: 1. CAPACIDAD INSTITUCIONAL DE GÉNERO: Planes de Igualdad, 35\%; Concejalías de Igualdad individualizadas, 25\%; Mesas sectoriales, 15\%; Institucionalización de órganos contra la violencia de género (mesas locales contra la VG y unidades 
contribución de la acción a la equidad de género. Para valorar el grado de implantación de las políticas de género en los municipios considerados se han identificado cuatro dimensiones, presentes en el conjunto de acciones identificadas:

1. Capacidad institucional de género. Hace referencia a todas aquellas acciones de carácter institucional establecidas por las corporaciones municipales que tienen como objetivo el establecimiento de un producto jurídico, institucional o físico que respalde las políticas de género: Concejalías de Igualdad, Planes de Igualdad, Consejos Municipales de la Mujer, Casas de la Mujer, órganos municipales contra la violencia de género.

2. Capacidad conciliadora: actividades de conciliación de la vida familiar y laboral.

3. Capacidad de fomento del empleo y del autoempleo.

4. Empoderamiento. Todas aquellas acciones conducentes a una toma de conciencia sobre las situaciones de desigualdad de género.

Las puntuaciones obtenidas para cada una de las dimensiones han sido, posteriormente correlacionadas con tres variables territoriales, población total, gasto total en políticas sociales y de seguridad y gasto en políticas sociales y de seguridad per cápita. Los resultados de la correlación (cuadro 6) muestran como los aspectos más institucionales de la implantación de las políticas de género están directamente relacionadas con el volumen demográfico y los presupuestos municipales totales. Otros aspectos como el desarrollo de actividades de conciliación, promoción del empleo femenino y el desarrollo de actividades que propician el empoderamiento, aunque puedan tener cierta relación dependen mucho más del establecimiento de una línea política que decida su puesta en marcha, lo que viene a revalorizar el papel que una política comprometida con la acción puede tener. Por otra parte, el gasto medio per cápita en políticas sociales y de seguridad parece no tener ninguna relación con la implantación de políticas de género. En esta misma línea puede desarrollarse el comentario de los gráficos de dispersión elaborados con algunos resultados obtenidos, donde se pone en relación el tamaño demográfico y dos de las dimensiones evaluadas (capacidad institucional de género y capacidad conciliadora) (figuras 9 y 10).

especializadas de la policía local), 15\%; Casas, Institutos y organismos de la Mujer, de estudios de las mujeres y de género, $15 \%$. 2. ACTIVIDADES DE CONCILIACIÓN DE LA VIDA FAMILIAR Y LABORAL: Sensibilización y formación del empresariado local en prácticas de conciliación, 30\%; Talleres, cursos, y/o actividades con temática de conciliación, 25\%; Puesta en valor de los recursos municipales para la conciliación, 20\%; Publicación en Webs de los recursos municipales para la conciliación, $10 \%$; Actividades innovadoras de conciliación, como bancos del tiempo, $10 \%$ y talleres de cuestionamiento del rol de género en el ámbito del hogar, 5\%. 3. ACTIVIDADES DE FOMENTO Y FORMACIÓN PARA EL EMPLEO: Actividades de formación para el empleo (búsqueda activa de empleo, preparación de la entrevista de trabajo, etc.), 40\%; Fomento del autoempleo y formación de mujeres empresarias, 40\%; Cursos con contenidos profesionales destinados a mujeres: informática, inglés, nuevas tecnologías, diseño informático: $20 \%$. 4. ACTIVIDADES DE EMPODERAMIENTO: Pensamiento feminista y de género, $35 \%$; Actividades de sensibilización en el mundo educativo, 35\%; Creatividad y autoestima: $30 \%$. 
Cuadro 6

CORRELACIONES ENTRE LA PUNTUACIÓN PONDERADA DE LAS POLÍTICAS DE GÉNERO Y LAS VARIABLES TERRITORIALES MUNICIPALES

\begin{tabular}{|l|r|r|r|}
\hline \multicolumn{1}{|c|}{ Dimensiones de género } & Población & $\begin{array}{c}\text { Gasto total en } \\
\text { políticas sociales } \\
\text { y de seguridad }\end{array}$ & $\begin{array}{c}\text { Gasto per cápita en } \\
\text { políticas sociales y } \\
\text { de seguridad }\end{array}$ \\
\hline 1.Capacidad institucional de género & 0,877 & 0,823 & 0,187 \\
\hline 2. Capacidad conciliadora & 0,471 & 0,469 & 0,089 \\
\hline $\begin{array}{l}\text { 3. Capacidad de fomento del empleo y } \\
\text { del autoempleo }\end{array}$ & 0,572 & 0,581 & $-0,053$ \\
\hline 4. Empoderamiento & 0,431 & 0,335 & 0,083 \\
\hline Método estadístico de correlación: Pearson.
\end{tabular}

Fuentes: Elaboración propia a partir de las puntuaciones ponderadas obtenidas para la investigación (ver nota a pie de página) y de variables territoriales. Variables territoriales: Banco de datos municipal ALMUDENA (tablas de Población empadronada y de Gasto en seguridad, protección y promoción social de los presupuestos municipales liquidados consolidados, año 2009. El gasto per cápita se ha calculado con la población de 2009).

Figuras 9 y 10

POLITIICAS DE GÉNERO EN MUNICIPIOS DE LA COMUNIDAD MADRID EN RELACIÓN CON EL TAMAÑO DEMOGRÁFICO. GRÁFICOS DE DISPERSIÓN
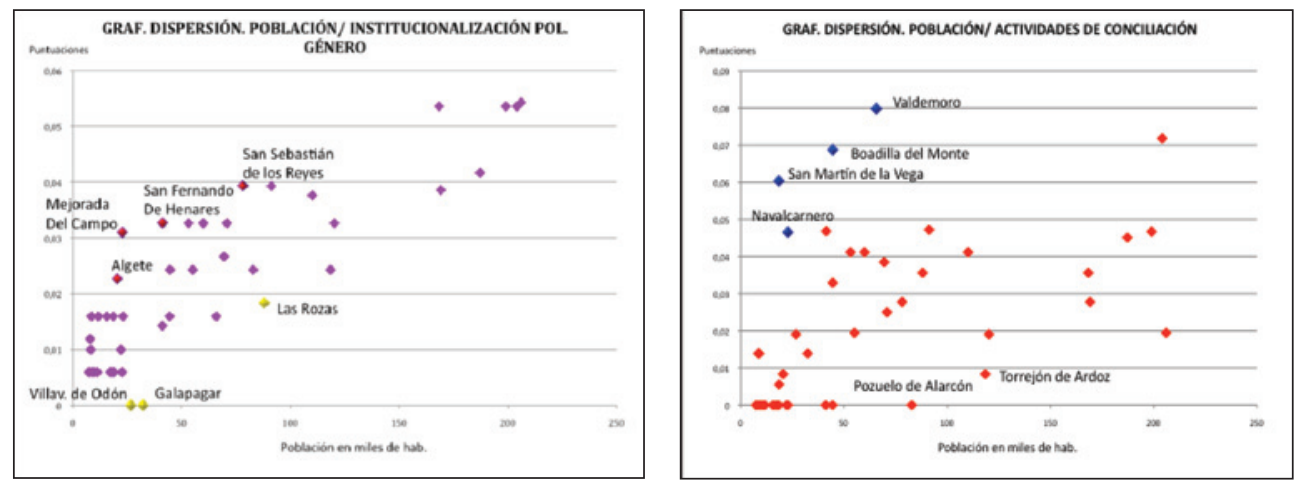

Fuente: elaboración propia

\section{CONCLUSIONES}

En este trabajo se ha pretendido realizar un retrato de las diferencias espaciales en la implantación de las políticas de igualdad de género en la Comunidad de Madrid. Se ha efectuado un análisis territorial que se apoya en la información obtenida de las páginas Webs municipales. Si se comparan los resultados con trabajos anteriores, donde también la escala municipal es relevante (Lombardo, 2002; Valiente, 1999), puede decirse que gran parte de los organismos institucionales -Concejalías de la Mujer, Mesas Sectoriales, Casas o Centros de 
la Mujer- ya estaban establecidos desde finales de la década de 1990, aunque no se disponía de información sobre su implantación territorial.

Un aspecto esencial de las políticas públicas de igualdad es que han ido evolucionando a lo largo de las últimas décadas en sus objetivos e instrumentos desde una perspectiva inicial de bienestar social a la transversalidad. En nuestra investigación se ha observado como todavía existe, lo que podemos denominar, «un doble discurso de la transversalidad». Ésta aparece contemplada en los documentos oficiales, especialmente en los Planes y en las Estrategias de Igualdad, sin embargo, las Webs municipales reflejan muy pocos esfuerzos por que la transversalidad se haga efectiva, mediante la formación del personal, político y técnico, de los ayuntamientos, la coordinación entre las diferentes áreas de gobierno y la elaboración de materiales donde se reflejen de forma integral recursos y actividades disponibles para satisfacer necesidades de las mujeres.

Desde el punto de vista de la implantación territorial de políticas de género, la mayoría de los municipios considerados presenta algún tipo, aunque el grado de desarrollo de éstas es muy heterogéneo. En este sentido, los resultados muestran una clara relación entre el grado de desarrollo de las políticas de igualdad y el tamaño demográfico del municipio aunque posiblemente este desarrollo no se deba tanto a la población total, como a la disponibilidad de mayores recursos económicos. Los municipios pequeños, con frecuencia, ven limitados sus recursos técnicos y presupuestarios y con ello, disminuidas sus posibilidades de implantar dispositivos extensos de igualdad, en parte porque se hace necesario atender otras necesidades que ocupan todo el presupuesto. En relación con esta idea debe reseñarse el papel que están jugando en la actualidad las Mancomunidades de Municipios y en muchas de ellas se constata la existencia de unidades de igualdad y la elaboración de Planes.

Por otra parte, nuestro análisis ha demostrado cómo municipios con similar población y prepuesto tienen comportamientos diferentes en cuanto al grado de desarrollo de las políticas de género, lo que denota una clara intencionalidad política por parte del equipo de gobierno. El papel ideológico debe, por tanto, entenderse en una doble perspectiva; se sabe que en su momento, el inicio de las políticas municipales de género estuvo ligado a determinas ideologías, por ejemplo municipios con partidos de izquierdas, como PSOE e IU, sin embargo en el momento actual, con una trayectoria de más de veinte años, independientemente del signo político del ayuntamiento, pocos son los consistorios que no presenten algún tipo de acción, bien por inercia - existe un entramado institucional consolidado- bien por corrección en el discurso político. No obstante debe incidirse en que el desarrollo integral de políticas de género en un momento dado, se debe a una decisión del equipo de gobierno, seguramente impulsado por una persona con sensibilización y formación en temática de género.

Otro aspecto a destacar es la importante presencia de actividades de sensibilización de género en la mayoría de las entidades locales; por ejemplo, la conmemoración del Día Internacional de la Mujer ( 8 de marzo) se desarrolla en casi todos los municipios analizados, al tiempo que más de la mitad desarrollan actividades de formación en temas de igualdad en los centros educativos, lo que indudablemente abre la puerta a la consecución de una sociedad más equitativa. Con similares objetivos debe mencionarse que los talleres, muy presentes en las actividades municipales, han diversificado su oferta, pasando a identificarse algunos con un objetivo claro de empoderamiento de las mujeres: autoestima, conocimiento personal, pensamiento feminista y de género, cambio de roles de género, visibilización de las mujeres en la sociedad y la Historia, ente otros. 
Los límites metodológicos de la investigación no han permitido, por otro lado, valorar aspectos que, sin duda, podrían complementarla. Uno que consideramos básico es el tema de los presupuestos municipales. Estudios similares a éste han señalado la escasa dotación de las acciones de igualdad en los presupuestos, lo que sin duda, limita de manera importante la implantación y eficacia de las acciones; la ausencia de presupuesto suficiente, en primer lugar, impide la formación cualificada del personal y además limita mucho el tipo de acciones a desarrollar, sobre todo aquellas que requieren de fondos económicos para apoyar efectivamente a las mujeres, como en la formación para el empleo o la puesta en valor de recursos de cuidado y protección a las personas dependientes. Esta limitación, sin duda, se está agudizando actualmente por la crisis económica y financiera en la que el Estado español, y con él la ciudadanía, se han visto atrapados. Posiblemente esta crisis debe estar generando un retroceso en los avances de las políticas de igualdad conseguidos hasta la fecha, con caídas en los recursos económicos de los últimos presupuestos y en todas las escalas (nacional, autonómica y local). De hecho, España ha sido el país que más puestos ha retrocedido en el Índice Global de Igualdad de Género que elabora anualmente el Fondo Económico Mundial, donde se evalúa a los países en función del grado de equilibrio social entre sexos, habiendo pasado del puesto 12 al 26 en el último año.

\section{REFERENCIAS BIBLIOGRÁFICAS}

ASTELARRA, J. (2005): Veinte años de políticas de Igualdad, Madrid, Ediciones Cátedra.

BACCHI, C.L. (1999): Women, policy and politics. The construction of policy problems, Londres, Sage.

BAREIRO, L. (1996): «Las recién llegadas: mujer y participación política», en Estudios Básicos de Derechos Humanos IV, Ed. IIDH y Comisión Europea, 219-251.

BAYBROOKE, D. y LIMDBLOM, C. (1963): A Strategy of Decision, Nueva York, The Free Press.

BOUZAS, R. y OTERO, P. (2011): «Las políticas municipales de género en España: estructuras de implementación y condicionantes», X Congreso de AECPA, Disponible en http:www.aecpa.es/congresos/10/ponencias166

BUSTELO, M. (2001): Evaluación de las políticas públicas de igualdad de género del gobiernos central y autonómicos en España. 1995-1999, Madrid, Facultad de Ciencias Políticas y Sociología, UCM.

BUSTELO, M. (2004): La evaluación de las políticas de género en España, Madrid, La Catarata.

BUSTELO, M. y LOMBARDO, E. (2004): «Mainstreaming de género y análisis de los diferentes marcos interpretativos de las políticas de igualdad en Europa: el proyecto Mageeq», Aequalitas: Revista jurídica de igualdad de oportunidades entre mujeres y hombres, $\mathrm{N}^{\circ} 17,15-26$.

BUSTELO, M. y LOMBARDO, E. (2006): «Los 'marcos interpretativos' de las políticas de igualdad en Europa: conciliación, violencia y desigualdad de género en la política», Revista Española de Ciencia Política, Vol. 14, 117-140.

CARBONE, M. (Eds.) (2006): New pathways in development: gender and civil society in EU policy, Aldershot, Ashgate. 
COMUNIDAD DE MADRID: www.madrid.org/cs/Satellite?blobcol...MUJER.pdf

DIRECCIÓN GENERAL DE IGUALDAD DE OPORTUNIDADES, Área de Gobierno de Familia y Servicios Sociales. Programa Operativo 2011 Estrategia para la Igualdad entre Mujeres y Hombres de la Ciudad de Madrid (2011-2015). Disponible en http://www. madrid.es/UnidadesDescentralizadas/IgualdadDeOportunidades/Ficheros/Programa\%20 Operativo\%202011.pdf.)

IEGE (THE EUROPEAN INSTITUTE FOR GENDER EQUALITY), Web de publicaciones: http://www.eige.europa.eu/content/publications

FEMP (Federación Española de Municipios y Provincias) (2006): Documento Marco para la Gestión de las Políticas Locales de Igualdad, Madrid, FEMP.

FEMP (Federación Española de Municipios y Provincias) (2009a): Guía para la constitución de Consejos Municipales de las Mujeres, Madrid, FEMP.

FEMP (Federación Española de Municipios y Provincias) (2009b): Guía para la Gestión de las Políticas Locales de Igualdad en los Gobiernos Locales de Municipios de menos de 10.000 Habitantes, Madrid, FEMP.

GELAMBÍ, M. (2005): «Las políticas de género catalanas y lombardas», Ponencia presentada al VII Congreso de Ciencia Política y de la Administración, Madrid.

GUZMÁN, V. (1997): «Equidad de género como tema de debate y de políticas públicas», en Feminismo en transición. Transición con feminismo, Memoria del Foro Internacional sobre Ciudadanía, Género y Reforma del Estado, México, Grupo de Educación Popular con Mujeres, A. C., 1-16.

HAUSSMAN, M. y SAUER, B. (Ed.) (2007): Gendering the State in the Age of Globalization: Women's Movements and State Feminism in Postindustrial Democracies, Nueva York, Rowman \& Littlefield Publishers.

LIMDBLOM, E. (1990): El proceso de formación de las políticas públicas, Madrid, MAP.

LOMBARDO, E. (2002): «Políticas de igualdad de género en los Ayuntamientos de Barcelona: origen, características y retos para el futuro», Gestión y Análisis de Políticas Públicas, no 23, 79-93.

LOMBARDO, E. (2004): La europeización de la política española de igualdad de género, Valencia, Tirant lo Blanch, 17-51.

MACKINNON (1989): Toward a feminist theory of the state, Cambridge (E.U.), Harvard University Press.

MARTÍNEZ, L. y ESCAPA, R. (2008): Guía de formación para la participación social y política de las mujeres Manual de la alumna, Ayuntamiento de Fuenlabrada, Concejalía de Igualdad y Empleo. Disponible en: http://www.educacionenvalores.org/IMG/pdf/guia_alumna_-_igualdad.pdf

MAZUR, A. (2002): Theorizing feminist policy, Oxford, Oxford University Press.

MOLINEAUX, M. (1985): «Movilization without emancipation? Women's Interest, State and Revolution in Nicaragua», Feminist Studies, vol. 11, n 2, 227-254.

MOSER, C. (1989): «Gender planning in the third world: Meeting practical and strategic gender needs», World Development, Vol. 17, Issue 11, November, 1799-1825. 
PETERSON, E. (2005): «Entre Trabajadoras, Cuidadoras y Empleadas Domésticas: Formando el discurso político sobre la conciliación de la vida familiar y laboral en España», Congreso AECPA, Universidad Complutense, Madrid, Disponible en:

http://www.aecpa.es/uploads/files/congresos/congreso_07/area06/GT22/PETERSONElin(UCM).pdf

RODRÍGUEZ, M. J. y NAVARRO, C. (2012): «La feminización de la dinámica política municipal. El caso de los municipios españoles», Revista Internacional de Sociología, Vol. 70, n 1, 181-201.

RODRÍGUEZ SANTOS, E. (2010): «Las Políticas de igualdad de género en las relaciones de trabajo y las comunidades autónomas», en Los nuevos marcos de Relaciones Laborales en el renovado Estado de las Autonomías. XXI Congreso Nacional de Derecho del Trabajo y de la Seguridad Social, Barcelona, Disponible en:

fundacion.usal.es/aedtss/images/.../Estefania_Rodriguez_Santos.doc -

ROLDÁN, E. (Ed.) (2004): Género, Políticas locales e Intervención Social. Análisis de los Servicios de Bienestar Social Municipal para la Población Femenina en España, Madrid, Editorial Complutense.

RUIZ, R. (2009): Principio de Igualdad entre hombres y mujeres. Del ámbito público al ámbito jurídico familiar, Murcia, Universidad de Murcia. Disponible en: http://www.tesisenred.net/bitstream/handle/10803/10750/RuizCarbonell.pdf?sequence=1 .

SABATÉ, A. et al. (2008): Hacia un sistema de Indicadores de Género en España: Un análisis territorial, Madrid, Instituto de la Mujer. Disponible en: http://www.migualdad.es/mujer/mujeres/estud_inves/729.pdf

SAINSBURY, D. (Ed.) (2000): Gendering welfare states, Londres, SAGE.

SAMPEDRO, M.R. (1992): Administración Local y Políticas de Igualdad de la Mujer, Madrid, FEMP.

THRELFALL, M. (1990): «¿Patriarca, palanca, paraguas? Planteamientos feministas en torno al Estado asistencial», en Astelarra, Participación política de las mujeres, Madrid, Centro de Investigaciones Sociológicas, 215-233.

VALIENTE, C. (1999): «Feminismo de Estado en los ayuntamientos de la Comunidad Autónoma de Madrid», Gestión y Análisis de Políticas Pública, 13/14, 173-189.

VALIENTE, C. (2005): «La efectividad de los organismos de igualdad: el estado de la cuestión en el ámbito internacional», en De la Fuente, M., Repensar les polítiques de gènere des de l»àmbit local, Barcelona, Institut de Ciénces Politiques i Socials, 79-102.

VALIENTE, C. (2006): El Feminismo de Estado en España: El Instituto de la Mujer (19832003), Valencia, Institut Universitari d'Estudis de la Dona.

WALBY, S. (2004): «The European Union and Gender Equality: Emergent Varieties of Gender Regime», Social Politics, Vol. 11, Issue 1, 4-29.

YOUNG, K. (1988): Women and economic development: local, regional, and national planning strategies, París, UNESCO. 
